\title{
Radiation Concerns for the Neuroanesthesiologists
}

\author{
Sourav Burman ${ }^{1} \quad$ Abanti Das ${ }^{2} \quad$ Charu Mahajan ${ }^{1} \quad$ Girija P. Rath ${ }^{1, \odot}$ \\ ${ }^{1}$ Department of Neuroanaesthesiology and Critical Care, \\ Neurosciences Centre, All India Institute of Medical Sciences, \\ New Delhi, India \\ 2Department of Radiology, Vardhman Mahavir Medical College and \\ Safdarjung Hospital, New Delhi, India

\begin{abstract}
Address for correspondence Charu Mahajan, MD, DM, Department of Neuroanaesthesiology and Critical Care, Neurosciences Centre, All India Institute of Medical Sciences, New Delhi110029, India (e-mail: charushrikul@gmail.com).
\end{abstract}

J Neuroanaesthesiol Crit Care:2021;8:3-11

\begin{abstract}
With the advent of minimally invasive neurosurgical techniques and rapid innovations in the field of neurointervention, there has been a sharp rise in diagnostic and therapeutic modalities requiring radiation exposure. Neuroanesthesiologists are currently involved in various procedures inside as well as outside the operating room (OR) like intensive care units, interventional suites, and gamma knife units. The ambit expands

Keywords

- radiation exposure

- radiation safety

- operating room

- neurointervention

- anesthesia from short-lasting diagnostic scans to lengthy therapeutic procedures performed under fluoroscopic guidance. Hence, a modern-day neuroanesthesiologist has to bear the brunt of the radiation exposure in both inside and outside the OR. However, obliviousness and nonadherence to the relevant radiation safety measures are still prevalent. Radiation protection and safety are topics that need to be discussed with new vigor in the light of current practice.
\end{abstract}

\section{Introduction}

With the advent of new modalities of imaging and imageguided interventions, the risk of radiation exposure ( $R E)$ has increased exponentially. Simultaneously, the ambit of neuroanesthesiologists has expanded from administering anesthesia inside operating room (OR) to managing patients outside the OR. These also include an increasing number of procedures that lead to RE ( - Table $\mathbf{1}$ ). The exposure in OR can range from single or multiple radiation shots during the use of mobile image intensifier (C-arm), two-dimensional/three-dimensional (2D/3D) imaging system $(\mathrm{O}-\mathrm{arm})$, and intraoperative computed tomographic (CT) scan. Substantial risk of RE occurs in neurointerventional radiology suites where live fluoroscopic imaging is used during a procedure. Gamma knife units pose quite a low risk of RE to neuroanesthesiologists provided standard prerequisites are followed. Other procedures such as X-ray and portable bedside CT scans in intensive care unit (ICU) also cause RE. Hence, a modern-day neuroanesthesiologist has to bear the brunt of the RE both inside and outside the OR.

Published online

December 27, 2020
DOI https://doi.org/

10.1055/s-0040-1715354

ISSN 2348-0548.

\section{Risk and Awareness}

It is likely that neuroanesthesiologists, in spite of being remarkably exposed to radiation, may forego all the necessary measures that ought to be undertaken. Maghsoudi et al analyzed the amount of radiation received by anesthesiologists posted at various places over a period of 3 months. On analyzing the badge readings, they found that anesthesiologists who are posted in high radiation areas such as catheterization laboratory, interventional radiology (IR) suite, and orthopaedic OR are more exposed to radiation as compared with those who worked in routine ORs. ${ }^{1}$ Similarly, Henderson et al found higher RE to the tune of 180 rem per month in anesthesiologists working in catheterization laboratory and high-risk areas. ${ }^{2}$ Pain physicians are exposed to significant radiation from fluoroscopy because of their proximity to the patients during procedures. ${ }^{3}$ Roguin et al stressed on the fact that the physicians who worked for long hours in the radiology suite were at high risk of carcinogenesis. ${ }^{4}$ A Turkish survey comprising of 491 practicing anesthesiologists showed that the awareness is very poor among the residents followed by the consultants. The

(c) 2020. Indian Society of Neuroanaesthesiology and Critical Care.

This is an open access article published by Thieme under the terms of the Creative Commons Attribution-NonDerivative-NonCommercial-License, permitting copying and reproduction so long as the original work is given appropriate credit. Contents may not be used for commercial purposes, or adapted, remixed, transformed or built upon. (https://creativecommons.org/licenses/by-nc-nd/4.0/).

Thieme Medical and Scientific Publishers Pvt. Ltd. A-12, 2nd Floor, Sector 2, Noida-201301 UP, India 
Table 1 Sites of RE for neuroanesthesiologist

\begin{tabular}{|c|c|}
\hline $\begin{array}{l}\text { Inside the operating } \\
\text { room during }\end{array}$ & Outside the operating room \\
\hline $\begin{array}{l}\text { - Skull base surgery } \\
\text { - Spinal Instrumentation } \\
\text { - Deep brain stimulation } \\
\text { surgery } \\
\text { - Pain relief procedures } \\
\text { for head and spine }\end{array}$ & $\begin{array}{l}\text { - Neurointerventional proce- } \\
\text { dures for head and spine } \\
\text { - Portable X-ray for patients } \\
\text { admitted in neuro-ICU } \\
\text { - Bedside CT scan for patients } \\
\text { admitted in neuro-ICU } \\
\text { - Gamma-knife procedures }\end{array}$ \\
\hline
\end{tabular}

Abbreviations: $\mathrm{CT}$, computed tomography; ICU, intensive care unit; RE, radiation exposure.

study observed that professors reported the highest rate (43\%) and residents reported the lowest rate of compliance (5.1\%) for adopting protective measures. ${ }^{5}$ Hence, less experienced personnel who were exposed to longer working hours in the catheterization laboratory were more exposed to hazardous radiation due to noncompliance in wearing lead aprons. Anastasian et al demonstrated that there is up to three times more facial RE to the anesthesiologists than the interventionalists. ${ }^{6}$ This might be because of the typical configuration of fluoroscopy equipment that directs scatter radiation away from radiologist and toward the anesthesiologist. The ignorance of neuroanesthesiologists can make them vulnerable to all harmful effects of ionizing radiation.

\section{Physics of Radiation}

Various units are used to measure dose of radiation and exposure. The amount of radiation travelling through air gives a value of RE measured in roentgen (U.S unit) or coulomb/ $\mathrm{kg}$ (SI unit). On the other hand, amount of radiation dose absorbed by matter is known as radiation absorbed dose or rad (U.S unit). In SI derived units, it is replaced by gray (Gy), where $1 \mathrm{~Gy}=100 \mathrm{rad}$. Both these terms help in measuring the absorbed dose. Effective dose measures the amount of radiation absorbed by a person, considering biological response of different tissue and organs to different types of radiation. The roentgen-equivalents-man or rem (U.S unit) is equal to rad multiplied by quality factor (QF), where rad is the amount of energy deposited per unit weight of human tissue and QF is a number assigned to different types of ionizing radiation. ${ }^{7}$ Sievert is a SI unit for the effective dose of radiation where $1 \mathrm{~Sv}=100 \mathrm{rem}$. For gamma and X-rays, $1 \mathrm{rad}=1 \mathrm{rem}=10 \mathrm{mSv}$. The power of the radiation beam follows the inverse square law $\left(1 / \mathrm{d}^{2}\right)$ that means the farther is the subject from the radiation source, the lesser is the RE. ${ }^{8}$

\section{Dosimetry}

The measurement of radiation doses is done by the portable dosimeters or thermoluminescent dosimeter badge that should be worn by all personnel working in radiation prone areas. The dose limits of exposure are expressed as equivalent dose $\left(\mathrm{H}_{\mathrm{T}}\right)$ for an organ or body part and effective dose for the exposure of total body. ${ }^{9}$ Equivalent dose is calculated by the mean absorbed dose multiplied by the radiation weighing factor $\left(\mathrm{W}_{\mathrm{R}}\right)$. Effective dose is defined as the weighted average of equivalent doses of all organs and tissues of the body. The tissue weighing factor is maximum for breast, lung, colon and the least for skin, brain, salivary glands, and cortical bone. A typical dosimeter provides two values, the $\mathrm{Hp}$ (0.07) and Hp (10), which are the radiation absorption readings at 0.07 and $10 \mathrm{~mm}$ below the skin, respectively. ${ }^{10}$ The $\mathrm{Hp}$ (10) readings furnished from the collar dosimeter give good readings for exposure to the lens, neck, and the thyroid. Another dosimeter is recommended to be worn on the waist to calculate exposure to the trunk and the abdomen. There are several algorithms for calculation of effective dose from dosimeter readings. When two dosimeters are worn, the National Council on Radiation Protection and Measurements (NCRP) estimates the effective dose by combining the Hp (10) dosimeter readings obtained from both collar and the body. ${ }^{11}$

$$
\text { Effective dose (estimate })=0.5 \mathrm{H}_{\mathrm{w}}+0.025 \mathrm{H}_{\mathrm{N}} \text {. }
$$

where $\mathrm{H}_{\mathrm{N}}=$ reading obtained from dosimeter worn at neck outside protective apron

$\mathrm{H}_{\mathrm{w}}=$ reading obtained from dosimeter worn at waist or on chest under protective apron.

The accuracy of the dosimeter readings is, however, a matter of concern owing to the nonadherence or inappropriate placement of the badges. Badges should not be left at a place where it is exposed to the radiations; it causes hindrance in correctly measuring the radiation absorption.

\section{Radiation Hazards and Safe Dose Limits}

There are three types of ionizing RE sources: (1) direct exposure from the primary X-ray beam; (2) scattered radiation reflected from patient's body, table, or surrounding equipment; and (3) leakage from the X-ray tube. Scatter radiations are mainly responsible for $\mathrm{RE} .{ }^{12}$ This scatter radiation is of primary concern for neuroanesthesiologists.

Organs such as thyroid, bone marrow, lens of eye, breasts, ovaries, and testicles are sensitive to radiation. Effects that occur by chance and without a threshold level of dose, whose probability is proportional to the dose, and whose severity is independent of the dose is called as stochastic effect, for example, cancer. ${ }^{13}$ Deterministic effect is defined as the effect directly related to the radiation dose that leads to direct cell injury or death, for example, skin damage and cataract. Exposure to ionizing radiation can lead to cellular damage via the induction of DNA lesions and the production of reactive oxygen species. These effects often result in cell death or genomic instability, leading to various radiation-associated pathologies including an increased risk of malignancy. ${ }^{14}$ The effect of ionizing radiation has probability of causing cancer or genetic damage. In the recent years, there are reports linked to developmental delay and neurotoxic effects. ${ }^{15}$ Studies on infant mice have shown that exposure to ionizing radiations has led to lack of habituation, impaired learning, 
and memory. Extensive research done in determining the effect of RE on eyes suggested it to be directly proportional to the radiation dose. ${ }^{3}$ The minimum dose that can cause lenticular cataracts has been documented at $0.1 \mathrm{~Gy}$ (gray). ${ }^{16}$ In cases of pregnant neuroanesthesiologists, one extra dosimeter should be worn over the abdomen under the apron. This may be considered as surrogate for radiation absorption to the fetus. ${ }^{8}$ However, it may overestimate the exposure as the impedance provided by the maternal tissues to the radiation absorption will not be taken into account. If pregnancy is confirmed, the cumulative dose should not exceed 1 millisievert ( $\mathrm{mSv}$ ) for the remaining period of gestation. The first trimester is the most sensitive time for radiations. Exposure above $10 \mathrm{mSv}$ is predicted to increase the risk of cancer by $0.1 \%$, in the fetus. ${ }^{17}$ The concern of the neuroanesthesiologist who is continuously exposed to such radiation prone environment has not been adequately addressed.

The International Commission on Radiation Protection (ICRP) has given the effective dose limits for various sites of exposure ( - Table 2 ). ${ }^{8}$ The dosimeters should be evaluated by the institutional medical physicist at least once a year. The report should be sent to the department as well as to the individuals on yearly basis. There should be a strict surveillance of the occupational doses; WHO recommends investigation when the effective dose exceeds $0.5 \mathrm{mSv} / \mathrm{month} .{ }^{19} \mathrm{In}$ such cases, the radiation officer should find out the cause of such high RE and appropriate action is taken.

\section{Existing Guidelines}

The ICRP suggests the goal of RE to be "as low as reasonably allowable (ALARA)" and a dose limit of $10 \mathrm{mSv} /$ year for 5 years. ${ }^{20}$ There are two basic tenets of the ALARA principle:

Table 2 Comparative dose limits of radiation exposure from two different regulatory bodies

\begin{tabular}{|l|l|l|}
\hline $\begin{array}{l}\text { Dose } \\
\text { quantity }\end{array}$ & $\begin{array}{l}\text { Occupational dose } \\
\text { limit (ICRP) }\end{array}$ & Dose limit (BARC) \\
\hline Effective dose & $\begin{array}{l}20 \mathrm{mSv} / \text { year } \\
\text { averaged over } \\
5 \text { consecutive years } \\
\text { (100 mSv in 5 years) }\end{array}$ & $\begin{array}{l}100 \mathrm{mSv} \text { in } \\
\text { consecutive } 5 \text { years } \\
20 \mathrm{mSv} \text { annual } \\
\text { average } \\
30 \mathrm{mSv} \text { in any year }\end{array}$ \\
\hline $\begin{array}{l}\text { Pregnant } \\
\text { worker }\end{array}$ & $\begin{array}{l}\text { Cumulative exposure } \\
\text { less than } 0.1 \mathrm{mSv} / \\
\text { month }\end{array}$ & $150 \mathrm{mSv} /$ year \\
\hline $\begin{array}{l}\text { Equivalent } \\
\text { dose in: }\end{array}$ & $20 \mathrm{mSv} /$ year & $500 \mathrm{mSv} /$ year \\
\hline Ocular lens & $500 \mathrm{mSv} /$ year & $500 \mathrm{mSv} /$ year \\
\hline Skin & $500 \mathrm{mSv} /$ year & $1 \mathrm{mSv} /$ year \\
\hline $\begin{array}{l}\text { Hands and } \\
\text { feet }\end{array}$ & & \\
\hline $\begin{array}{l}\text { Lifetime } \\
\text { effective dose }\end{array}$ & & \\
\hline
\end{tabular}

a $1 \mathrm{mSv}=100 \mathrm{mRem}$.

Adapted from International Commission on Radiological Practice (ICRP) and Bhabha Atomic Research Centre (BARC) newsletter. ${ }^{8,18}$
- Procedure should be performed only when it is absolutely necessary

- Keep the fluoroscopic dose to the minimum that is absolutely necessary

The consensus guidelines of Joint Commission of Cardiology and Interventional Radiology Society of Europe (CIRSE) and the Society of Interventional Radiology (SIR) acknowledge that during interventional procedures the concern for radiation safety has been neglected, especially in developing countries. ${ }^{21}$ The anesthesiologist, who most of the time remains inside the radiology suite and hence, is equally exposed to radiations as the primary physician. ${ }^{22} \mathrm{As}$ the neuroanesthesiologist is unable to control the duration of exposure, protective measures should be strictly adopted and adequate distance should be maintained to minimize the harmful effects of radiation. It also requires care of the ergonomics and equipment standards.

\section{Specific Modalities of Radiation}

\section{Portable X-Ray}

Portable X-ray used for routine imaging in the ICU (Mobility HP, Siemens, California, United States) operates in a wide range of power starting from $30 \mathrm{Kw}$ to $450 \mathrm{~mA}$ and provides a rapid image acquisition with improved clarity (-Fig. 1). The RE is calculated from the dose area product (DAP). A standard X-ray exposure ranges from 2100 to $3400 \mathrm{mRad}$ for anteroposterior and lateral images. ${ }^{23} \mathrm{~A}$ study showed that the exposure is minimum at a distance of 6 feet or 36 inches from the source of X-ray. ${ }^{24}$

\section{Conventional Fluoroscopy, C-Arm and O-Arm}

With the advent of $\mathrm{C}$-arm and $\mathrm{O}$-arm, complex spine surgeries can be now performed meticulously. In the C-arm, the X-ray tube and image intensifier are both aligned by

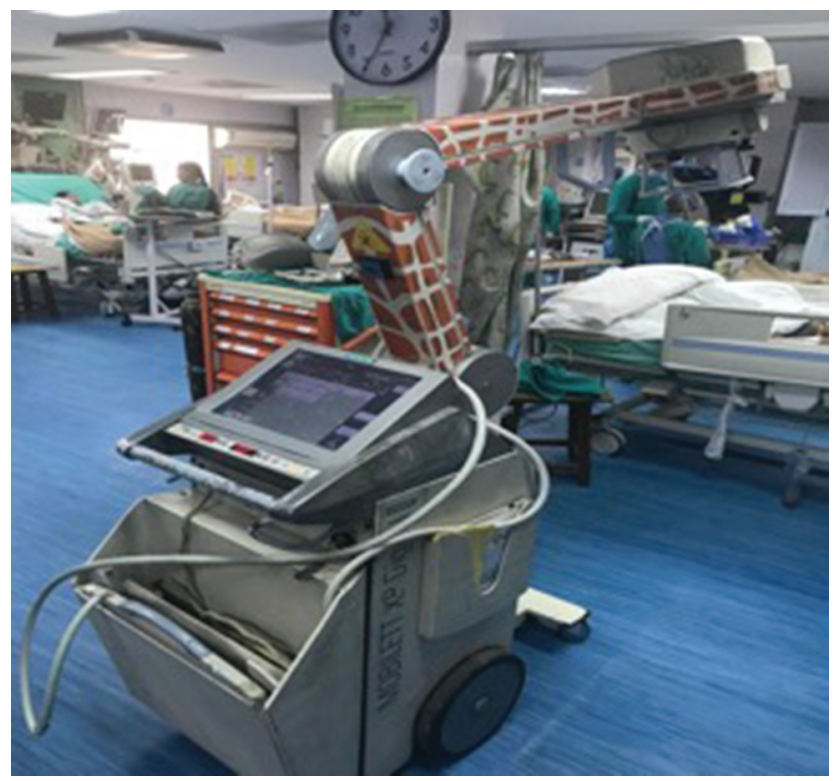

Fig. 1 Portable X-ray machine in neurointensive care unit. 
means of a c-shaped element that enables image retrieval at almost any angle (-Fig. 2A). In case of standard C-arm, the $\mathrm{RE}$ is $\sim 0.2 \pm 1.8 \mathrm{mSv}$ for imaging of thoracolumbar spine procedures. ${ }^{25}$ The newer 3D isocentric C-arm offers advanced features such as image reconstruction and CT-like images unlike conventional fluoroscopy. The O-arm has a 360-degree circular arc capable of acquiring 2D/3D images along with the possibility of carrying out image-guided spine surgeries (-Fig. 2B). It has the capacity for acquiring 750 images in a single scan. In a single shot, RE ranges from $30 \pm 4 \mu \mathrm{Gy}$ to $20.0 \pm 3.0 \mathrm{mGy}$ for spine procedures. For a single $3 \mathrm{D}$ acquisition, the maximum ambient equivalent dose at $2 \mathrm{~m}$ from the isocenter was $11 \pm 1 \mu \mathrm{Sv}^{26}$ The amount of $\mathrm{RE}$ can be decreased by allowing the surgical staff to leave the room.

\section{Computed Tomography Scan}

Patients are often subjected to CT scan of head or spine during perioperative period. Bedside CT scans have been made feasible with the availability of portable machines ( - Fig. 3A), which obviates the need for shifting the patient to a radiology facility. A CT operative suite with an integrated image guidance system facilitates high-quality CT imaging that helps in carrying out surgery more accurately (-Fig. 3B). It also allows revision of instrumentation, before final surgical closure. The accuracy of intraoperative CT has been observed to be comparable to $\mathrm{O}$-arm for spinal instrumentation. ${ }^{27}$

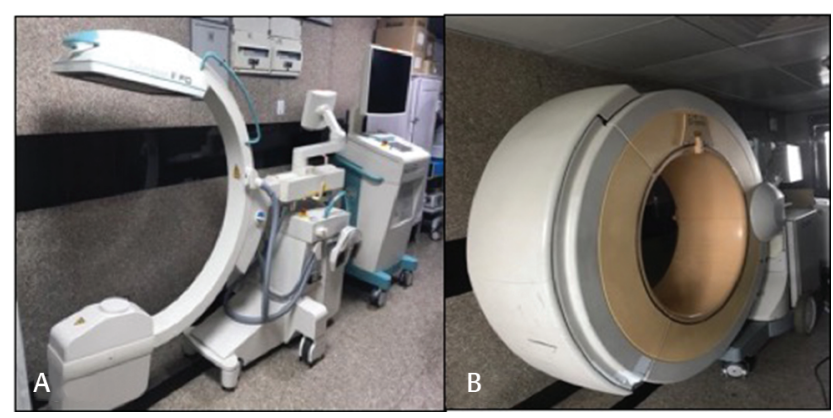

Fig. 2 (A) C-arm assembly. (B) O-arm unit.

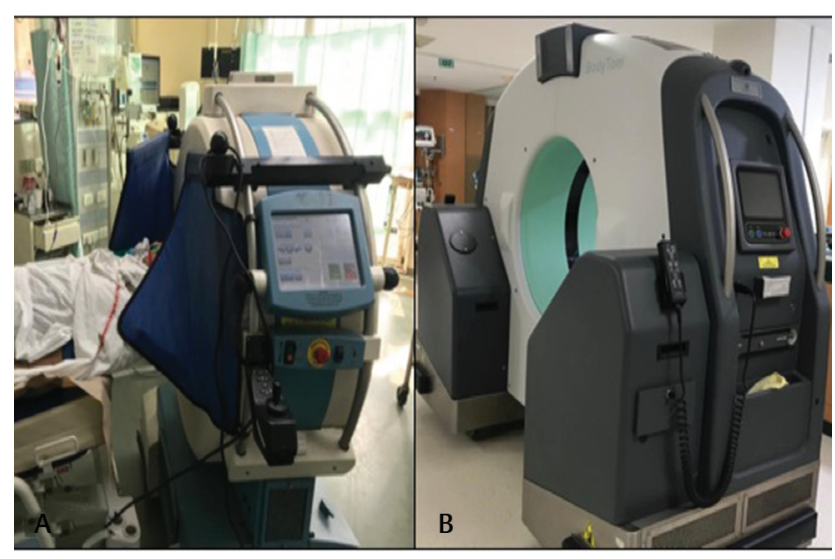

Fig. 3 (A) Portable computed tomography (CT) scan machine in neurointensive care unit. (B) CT machine for intraoperative use. (Courtesy: Max Hospital, Saket, New Delhi).

\section{Exposure during Different Procedures}

\section{Microscopic Pituitary Surgery}

Conventional fluoroscopy provides radiological guidance to identify sella and guides the surgical trajectory to approach the tumor. This helps in improving the resection quality and approach during pituitary surgeries. CT-based neuronavigation offers more detailed 3D anatomy during pituitary surgeries but is associated with higher RE to patients. ${ }^{28}$ However, in recent times endoscopic surgery with stereotactic navigation has obviated the need for RE.

\section{Spine Surgeries}

The imaging modalities such as portable X-ray, C-arm fluoroscopy, and O-arm are important for the localization of level of spine as well as facilitating spinal instrumentation. However, the RE can be significant depending upon the duration of exposure and complexity of the procedure. Yu and Khan carried a systematic review and found that there is more RE in noninvasive or minimally invasive spine surgeries as compared with open spine surgeries. This can possibly be due to more reliance on imaging modalities during these procdeures. ${ }^{29}$ The newer imaging modalities and spinal navigation systems have been developed in an effort to replace conventional fluoroscopy and reduce RE. ${ }^{30}$ Typically, an imaging mechanism is used to collect radiographic images that are then imported into a computer workstation that creates a $3 \mathrm{D}$ reconstruction of the anatomy of interest. The various types of imaging devices integrated with navigation are isocentric C-arm, O-arm, and CT-guided navigation. Various anthropometric and phantom-based models have been used by researchers who found that the CT-guided navigation systems resulted in low RE as compared with standard fluoroscopic techniques. ${ }^{31,32}$ The time needed for procedures has also been found to be less in C-arm-guided navigation systems as compared with standard fluoroscopy. The isocentric C-arm use has been found to be associated with lower total mean RE to the surgeon's torso ( 0.33 vs. 4.33 mREM) as compared with standard fluoroscopy. ${ }^{33}$ Similarly, the O-arm is programmed with preset modes that optimize kilovoltage and milliampere settings for various patient sizes and anatomical regions. Nelson et al designed an experimental model to determine the amount of RE to patients and OR staff during spine surgery. ${ }^{23}$ The anesthesiologist received highest RE during O-arm followed by portable X-ray and the C-arm acquisitions. On the other hand, radiology technologist and surgeon receive most RE during portable X-ray, followed by the $\mathrm{O}$-arm and $\mathrm{C}$-arm image acquisitions. This difference can possibly be owed to the respective standing position of staff in the OR. In a recent systematic review, RE by different imaging technology was assessed during thoracolumbar spinal fusion. ${ }^{34}$ The authors found that intraoperative CT imaging offered the lowest surgeon and OR staff RE, while increasing intraoperative patient $\mathrm{RE}$ relative to both conventional fluoroscopy and fluoroscopy with preoperative CT-based navigation. The least RE during intraoperative $\mathrm{CT}$ imaging can be explained by surgeon and staff stepping outside the OR when scan is run. Overall patient RE remains well below safety 
levels for both intraoperative CT and fluoroscopy-based techniques and it also eliminates need for preoperative and postoperative CT scans.

\section{Neurointerventional Suite}

Patients having neurovascular conditions such as cerebral aneurysms, acute ischemic stroke, arteriovenous malformations, or fistula are often subjected to diagnostic and therapeutic procedures in neurointerventional suite. Amount of RE depends upon the length and complexity (diagnostic or therapeutic) of the procedure. Digital subtraction angiography (DSA) is a commonly performed fluoroscopic procedure used for real-time visualization of blood vessels. ${ }^{35}$ The net exposure during DSA will depend on the fluoroscopy time and the number of runs taken. On an average, the range of exposure is around 17.4 ( $\mathrm{SD} \pm 0.5$ ) $\mathrm{mGy}$ in posteroanterior plane and 13.2 (SD \pm 0.2 ) $\mathrm{mGy}$ in lateral planes. ${ }^{36}$ The conventional four- or six-vessel DSA contributes to a radiation dose of $21.5 \pm 0.5 \mathrm{mGy}$. To reduce the exposure, one such technique is the use of fluoroscopy in pulsed and low-dose mode. Pulsed mode refers to a method where power to the radiation source is applied intermittently producing short pulses of radiation, while low-dose mode reduces the peak kilovolts and $\mathrm{mA}$ necessary to create the radiation beam. Other dose reduction techniques include intermittent fluoroscopy and last image hold. Intermittent fluoroscopy refers to applying fluoroscopy only for short time periods, while last image hold displays the last collected image even when fluoroscopy is not being applied. These methods allow for both reduced total fluoroscopy time and the ability to better plan surgical approaches through image review. Anastasian et al measured the amount of radiation to the face and the eyes of the anesthesiologist, and found that there is a six fold increase in the RE during neurointerventional procedures. ${ }^{6}$ The exposure was more than three times the exposure to the radiologist possibly due to the configuration of the horizontal fluoroscopy that subjects the anesthesiologist to more scatter radiation. It was concluded that the RE was higher than permissible limits, and anesthesiologist should wear protective eye gear during such procedures. Injections of drugs or alterations in pump settings would normally draw the anesthesiologist toward the intravenous tubing and, thus, toward the patient's head, closer to the source of scatter radiation. Similarly, switching the anesthesia ventilator off to provide an apneic patient during imaging would do the same. Thus, it is recommended to constantly stay behind the 6 feet long, $0.5 \mathrm{~mm}$ lead drape, to place all the tubings, injection ports, and infusion devices behind the protective lead curtain, and to maintain a distance from the fluoroscopic beam. Modern interventional neuroradiology suites generally use biplanar equipment with one $\mathrm{C}$-arm in the anteroposterior plane and one C-arm aimed laterally (-Fig. 4). The neuroanesthesiologist receives comparatively less scatter radiation by standing on the side of the image intensifier rather than standing on the same side as radiograph tube. ${ }^{6}$ Whenever feasible, one should emerge from behind the shield only when the fluoroscopy is off.

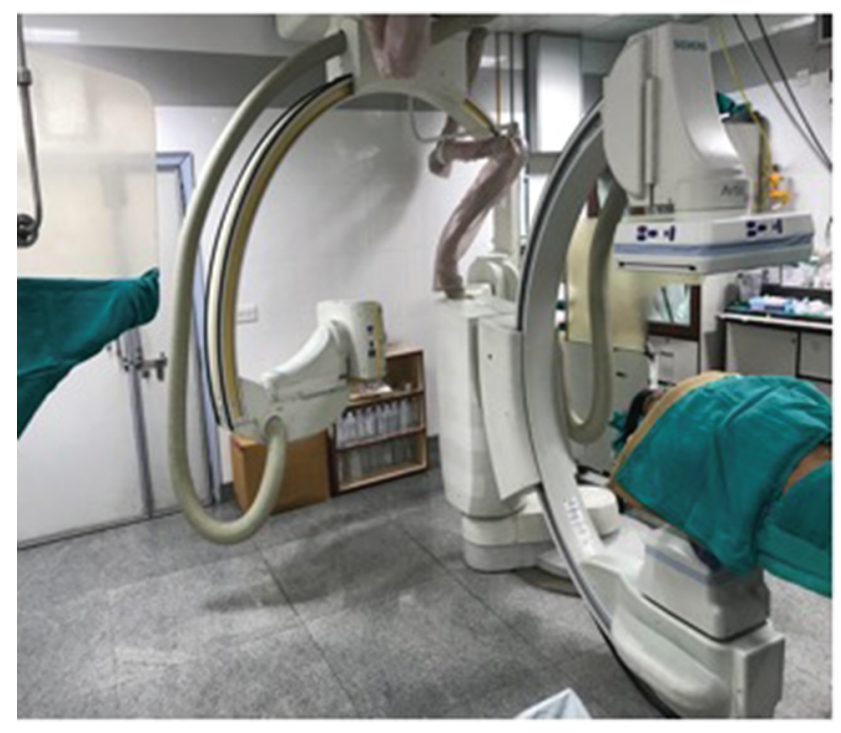

Fig. 4 A biplanar digital subtraction angiography unit.

\section{Pain Procedures}

During pain ablation procedures of head and spine, fluoroscopy is used to identify the anatomic bony landmarks as well as to direct the needle trajectory toward the area of interest. This exposes the neuroanesthesiologist to significant radiations because of the repetitive exposure and proximity to the patient especially during procedures for facial pain. Telischak et al have developed a novel technique using C-arm and CT guidance to form a 3D image-based technique that decreases the procedural time and improves the patient comfort. ${ }^{37}$ However, whether the amount of RE is more or less than the conventional technique is not yet known. Pain procedures carried under fluoroscopy guidance need to follow same precautions to reduce RE as any other fluoroscopic-guided procedure. $^{38}$

\section{Radiation Exposure in Neuro-ICU}

Portable X-ray and bedside head CT scanner are used in ICU for imaging and point-of-care testing. Fan Chiang et al found that the average exposure from bedside X-ray machines in ICU is around $0.24 \pm 0.04 \mathrm{mSv}$ at a distance of $4 \mathrm{~m}$ from the scanner. ${ }^{39}$ The average is $1.04 \mathrm{mSv} / \mathrm{year}$ in ICU staff. The portable CT scan has 4000 times more RE than a simple chest X-ray and on an average effective dose for a routine head CT examination is around $1.7 \mathrm{mSv} .^{30}$ The dose may range from 1 to $2 \mathrm{mSv}$ for a routine noncontrast CT scan head. Owing to several times these CT scans are repeated especially in the postoperative setting, the cumulative exposure to neurointensivist may be alarmingly high if precautions are not taken. During CT scan of head, the continuous RE is around $2.5 \mu \mathrm{sv} / \mathrm{sec}$ at a distance of $5 \mathrm{~m} .{ }^{40}$ - Table 3 shows the effective dose limit for various radiological procedures.

\section{Gamma Knife Radiotherapy}

The role of gamma knife radiotherapy (GKRT) is evolving at a rapid pace for the treatment of craniopharyngiomas, 
Table 3 Effective dose limit for various radiological examinations

\begin{tabular}{|l|l|}
\hline Procedure & Effective dose (mSv) \\
\hline Chest X-ray & $0.02-0.05$ \\
\hline X-ray skull or neck & $0.1-0.2$ \\
\hline X-ray abdomen & $0.5-1.5$ \\
\hline CT head & $5-10$ \\
\hline Abdomen CT & $15-20$ \\
\hline
\end{tabular}

Abbreviation: $\mathrm{CT}$, computed tomography.

pituitary tumors, arteriovenous malformations, metastatic tumors, acoustic neuromas, and skull base tumors. ${ }^{41}$ During certain circumstances that require sedation or general anesthesia, the neuroanesthesiologist is involved in taking care of the patient. At the time when gamma therapy is being delivered, neuroanesthesiologist leaves the room and monitors the patient through a camera mounted outside the gamma knife room. The room is usually triple lead insulated ( - Fig. 5) and personnel enters only when required, wearing protective gear and badges. The procedure time may vary from 2 to 4 hours and the dose to the patient ranges from 10 to $100 \mathrm{~Gy}$ depending on the location and size of the tumor. ${ }^{42}$

\section{Radiation Safety Measures}

There is inverse square relationship between RE and distance that implies that if the person doubles the distance from the point source, the RE should be reduced to one fourth. Therefore, it is suggested to keep a far distance from the source during imaging to reduce RE. ALARA principle is the utmost thing to follow for reducing the RE. Every institution should formulate its radiation protection institutional protocol and spread awareness among the concerned personnel. There are several factors that are responsible for determining the scatter such as patient size, duration of fluoroscopy, gantry angulation, intensity of the beam, the metallic surfaces of different equipment, and cracks in the apron. ${ }^{32}$ The best way is to use appropriate shielding including the use of protective gear. - Table 4 enumerates the important protective measures that need to be adopted to minimize radiation risk.

\section{Protective Shielding}

There are three types of shielding available: architectural, equipment mounted, and personal protective devices. The architectural shielding hangs from the walls and includes drapes and transparent lead barriers. Combination of both wall hanging and trolley mounted lead should be used to screen radiation from the cathode ray beam ( - Fig. 6A). Shielding with lead barriers may reduce the exposure to scatter radiations by more than $50 \%{ }^{43}$ The equipment-mounted devices are the lead drapes, mounted on either side of the table that separates the X-ray collimator placed under the table from the operator (-Fig. 6B). Trolleys of transparent leaded plastic are used as they significantly reduce radiation to the eyes. A radiation protection drape placed over the patient's body confers protection from scattered radiation and

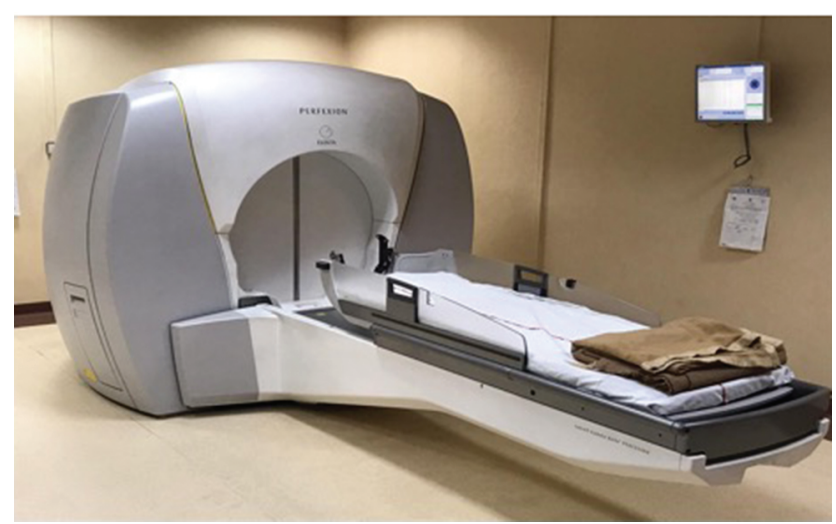

Fig. 5 Gamma knife unit.

Table 4 Measures to be adopted to reduce radiation exposure

\begin{tabular}{|c|c|}
\hline Parameter & Adoptive measures \\
\hline Distance & $\begin{array}{l}\text { - Maximize distance from the radia- } \\
\text { tion beam } \\
\text { - To stand on the side of the image } \\
\text { intensifier } \\
\text { - Position the image intensifier closer } \\
\text { to the patient to achieve maximum } \\
\text { magnification }\end{array}$ \\
\hline Shielding & $\begin{array}{l}\text { - Lead barrier shield } \\
\text { - Lead gloves and aprons } \\
\text { - Lead caps } \\
\text { - Thyroid shield } \\
\text { - Eye goggles with leaded large lenses } \\
\text { - Lead skirts surrounding the fluoros- } \\
\text { copy tables }\end{array}$ \\
\hline Imaging & $\begin{array}{l}\text { - Correct orientation of the beam to } \\
\text { reduce repeated exposure } \\
\text { - Collimation } \\
\text { - Using pulsed mode } \\
\text { - Intermittent needle advancement } \\
\text { - Last image hold } \\
\text { - Using low dose protocols } \\
\text { - Ergonomic design of intervention } \\
\text { laboratories }\end{array}$ \\
\hline $\begin{array}{l}\text { Regular } \\
\text { measurement }\end{array}$ & - Dosimeter badges \\
\hline Education & $\begin{array}{l}\text { - Regular education impartment to } \\
\text { adopt protective measures }\end{array}$ \\
\hline
\end{tabular}

has been suggested as a reasonable alternative when standard lead shielding is unavailable or impractical to use. ${ }^{44,45}$ These drapes contain bismuth and tungsten-antimony and can be used as lead alternatives. They are a bit costly, but provide good protection to the operator. In the wake of the new era on dynamic radiation protective gear, it has been long debated that the $0.5 \mathrm{~mm}$ lead equivalent aprons may have flaws in design. Thus, a team of researchers headed by Marichal et al designed the "ZeroGravity" (Zgrav) radiation protection system. ${ }^{46}$ It is a suspended lead suit (Interventco, 

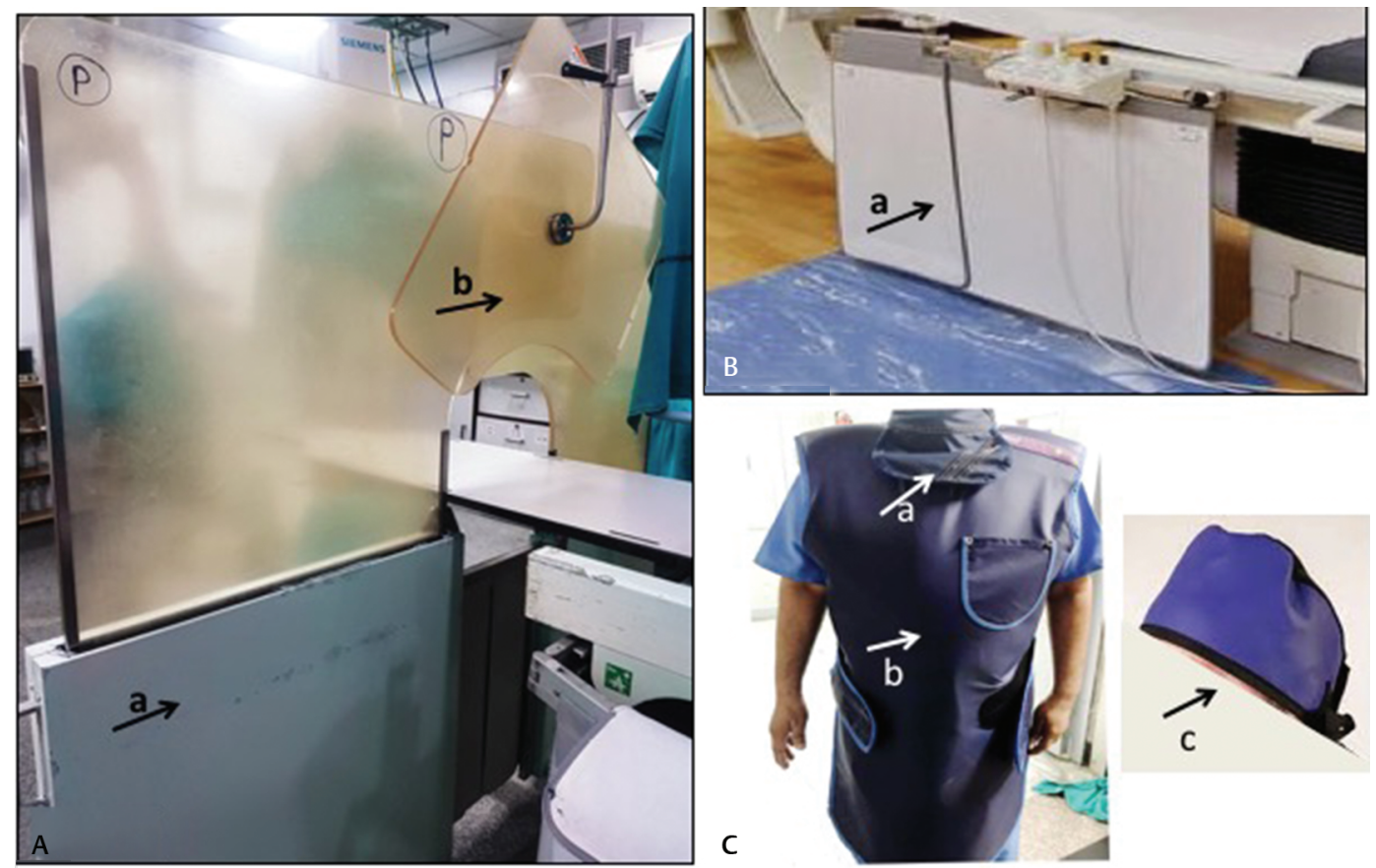

Fig. 6 Different types of radiation protective shielding. (A) The arrangement of architectural shielding during neurointervention procedures with arrows depicting (a) mobile lead screen and (b) ceiling-mounted lead screen. (B)Equipment (table)-mounted lead screen. (C) Arrows showing (a) front coverage lead apron, (b) thyroid shield, and (C) lead cap.

Dallas, Texas, United States), which provides radiation shielding from the top of the head to the calves (except the right arm and left forearm) via a complex overhead motion system to eliminate weight on the operator while maintaining freedom of motion in all three spatial axes and range of arm motion during procedures.

\section{Radiation Protection Gear}

Personal protection devices include the armamentarium of lead apron, thyroid shield, gloves, lead cap and eye gear ( - Fig. 6C). The different types of apron designs available are aprons with front coverage, wrap around, and a vest and kilt/skirt combination. The wrap around and vest/skirt configuration provide better protection where back is exposed to RE. These aprons should be at least $0.5 \mathrm{~mm}$ thickness in lead equivalent to provide $90 \%$ of protection from scatter radiation. It is important for these to have a proper fit for providing adequate coverage. For additional upper arm and lateral thorax protection, humeral arm shields may also be worn. These aprons need to be hanged properly and stored when not in use. Visual and tactile inspection should be done regularly in addition to the fluoroscopic inspection once yearly for cracks or damages as a quality control policy. ${ }^{47} \mathrm{~A}$ standard lead apron should protect $82 \%$ of the bone marrow, which still leaves a substantial amount exposed for radiation hazard. ${ }^{7}$ Lead dust produced from these aprons may cause environmental contamination. Depending upon their size, these can be quite heavy and may cause significant shoulder and back ache when worn for long period of time. The vest/skirt is more comfortable to wear than the front coverage aprons. A newer version of the light weight lead apron is available (weightless aprons) that are good alternatives to the old heavy lead variants. ${ }^{48}$ The shielding materials have changed from heavy lead impregnated vinyl rubber attires to the new lighter, composite lead along with high atomic number elements such as tungsten, bismuth, antimony, titanium, and magnesium. Protection ensured by $0.5 \mathrm{~mm}$ lead equivalence or lead-free aprons have been found to be around 0.6 to $6.8 \%$ of transmission. ${ }^{8}$ The choice of the apron should depend upon the working conditions, imaging protocols, use of other radiation protective shields, and personal health conditions (spine problems). In-house validation of aprons for radiation safety should be done as different aprons provide varied radiation protection even if labeled as having equal lead equivalence. ${ }^{49}$

Eyes are very sensitive to harmful effects of radiation, so, protective eye goggles with large lenses are recommended for lenticular protection. The amount of radiation protection with lead gloves is debatable..$^{50}$ It is better to avoid placement of hands in the direct projection beam because in that case gloves will provide limited hand protection. It may be of use in those cases where operator's hand is near the beam for long periods of time.

RE to the head leading to the possible development of tumors is a concern. Karadagz et al studied the efficacy of the lead cap in radiation protection of the head and compare it with that of a ceiling mounted lead glass screen in a real life setting. ${ }^{51}$ They found that a $0.5 \mathrm{~mm}$ lead equivalence was more effective than the mounted lead shields during routine interventional procedures. Even most of the users said that the lead cap was ergonomic in design and comfortable in wearing for long periods ( - Fig. $6 \mathbf{C C}$ ). 


\section{Design of the Catheterization Laboratory}

The design of the neuroradiology suite should be robust and should allow adequate radiation protective amenities. A large display monitor reduces the need for magnification and RE. An X-ray-shielded control window allows observation of the patient from the console room. Real-time projection monitors outside the main neuroradiology suite and in the console room allows the anesthesiologist to monitor the patient outside the suite. Proper radiation shielding of the laboratory is also necessary to prevent $\mathrm{RE}$ to adjacent occupancies.

\section{Imaging Techniques}

A technological upgradation from continuous fluoroscopy projection to use short taps of fluoroscopy beam is called "pulsed fluoroscopy." It is better as it cuts out the unnecessary continuous exposure in a case..$^{35}$ Alarm bells to remind the operator regarding the approximate exposure timing (e.g., 5 minutes) or live readouts help to warn the operator regarding the exposure. ${ }^{52}$ Other ways to reduce exposure are by low-dose fluoroscopy settings, spectral beam filtration, and use of antiscatter grid. Adjusting collimator settings to focus on the area of interest helps to reduce image intensity and exposure. Use of appropriate fluoroscopy instruments that comply with the International Electro Technical Commission Standards (IEC) is advocated.

\section{Radiation Safety Education}

Awareness and training should be organized for the neuroanesthesia personnel as most of the time, users are not aware of the risk. The misconception that "one which is not visible, is not harmful" needs to be erased from the minds. The MARTIR project (Multimedia and Audiovisual Radiation Protection Training in Interventional Radiology) developed a free training program and is a good self-evaluation tool. ${ }^{53}$ Training in awareness regarding radiation hazards has been imparted by the International Atomic Energy Agency (IAEA)..$^{54}$ In India, Bhabha Atomic Research Centre (BARC) is the monitoring agency for potential RE. From time to time, BARC publishes the safe recommended doses for different organs and effective doses of various modalities.

\section{Conclusion}

Overall, the neuroanesthesiologist is quite prone to the deterministic and stochastic effects of radiation, the extent of which is still largely unknown. The effects are dependent on many modifiable factors that should be taken into consideration during our day-to-day clinical practice. Ergonomic design, appropriate shielding, and personal radiation protective devices, all contribute to minimize RE. Constant monitoring of such RE must be done using appropriate adherence to dosimetry badge guidelines. Still a lot of ignorance and nonadherence remains in the field of radiation safety. Awareness programs and training curriculum should be our goal for better health of the neuroanesthesiologist working in the radiation zones.

Conflict of Interest

None declared.

\section{References}

1 Maghsoudi B, Mortazavi SMJ, Khademi S, Vatankhah P. Evaluation of radiation exposure pattern and radiation absorbed dose resulting from occupational exposure of anesthesiologists to ionizing radiation. J Biomed Phys Eng 2017;7(3):271-278

2 Henderson KH, Lu JK, Strauss KJ, Treves ST, Rockoff MA. Radiation exposure of anesthesiologists. J Clin Anesth 1994;6(1):37-41

3 Cheon BK, Kim CL, Kim KR, et al. Radiation safety: a focus on lead aprons and thyroid shields in interventional pain management. Korean J Pain 2018;31(4):244-252

4 Roguin A, Goldstein J, Bar O, Goldstein JA. Brain and neck tumors among physicians performing interventional procedures. Am J Cardiol 2013;111(9):1368-1372

5 Tüfek A, Tokgöz O, Aycan IÖ, Çelik F, Gümüş A. Current attitudes of Turkish anesthesiologists to radiation exposure. J Anesth 2013;27(6):874-878

6 Anastasian ZH, Strozyk D, Meyers PM, Wang S, Berman MF. Radiation exposure of the anesthesiologist in the neurointerventional suite. Anesthesiology 2011;114(3):512-520

7 Ismail S, Khan F, Sultan N, Naqvi M. Radiation exposure to anaesthetists during interventional radiology. Anaesthesia 2010;65(1):54-60

8 The 2007 Recommendations of the International Commission on Radiological Protection. ICRP publication 103. Ann ICRP 2007;37(2-4):1-332

9 Dagal A. Radiation safety for anesthesiologists. Curr Opin Anaesthesiol 2011;24(4):445-450

10 Michel R, Perle SC. Effective dose equivalent estimates in diagnostic radiology with single dosimetry. Health Phys 2000;79(2, Suppl):S17-S19

11 National Council on Radiation Protection and Measurements. Use of personal monitors to estimate effective dose equivalent and effective dose to workers for external exposure to lowLET radiation. NCRP Report No. 122. Bethesda MD: National Council on Radiation Protection and Measurements; 1995

12 Dendy PP. Radiation risks in interventional radiology. $\mathrm{Br} \mathrm{J}$ Radiol 2008;81(961):1-7

13 Gilbert ES. Ionising radiation and cancer risks: what have we learned from epidemiology? Int J Radiat Biol 2009;85(6):467-482

14 Kincaid OW. The problem of repeated exposure to radiation by anesthesiologists. Anesth Analg 1958;37(6):361-370

15 Manchikanti L, Cash KA, Moss TL, Rivera J, Pampati V. Risk of whole body radiation exposure and protective measures in fluoroscopically guided interventional techniques: a prospective evaluation. BMC Anesthesiol 2003;3(1):2

16 Valentin J. Avoidance of radiation injuries from medical interventional procedures. Ann ICRP 2000;30(2):7-67

17 International Commission on Radiological Protection. Conversion coefficients for use in radiological protection against external radiation. Adopted by the ICRP and ICRU in September 1995. Ann ICRP 1996;26(3-4):1-205

18 Pradeepkumar KS, Sharma DN, Khushwaha HS. Philosophy and principles of radiation protection, security of radioactive sources and preparedness for response to radiological emergencies. Barc Newsletter 2006;1(275):1-29

19 World Health Organization, Efficacy and Radiation Safety in Interventional Radiology. Geneva, Switzerland: World Health Organization; 2000

20 Bashore TM, Bates ER, Berger PB, et al; American College of Cardiology. Task Force on Clinical Expert Consensus Documents. American College of Cardiology/Society for Cardiac Angiography and Interventions Clinical Expert Consensus Document on cardiac catheterization laboratory standards. A report of the American College of Cardiology 
Task Force on Clinical Expert Consensus Documents. J Am Coll Cardiol 2001;37(8):2170-2214

21 Miller DL, Vañó E, Bartal G, et al; Cardiovascular and Interventional Radiology Society of Europe; Society of Interventional Radiology. Occupational radiation protection in interventional radiology: a joint guideline of the Cardiovascular and Interventional Radiology Society of Europe and the Society of Interventional Radiology. Cardiovasc Intervent Radiol 2010;33(2):230-239

22 Klein LW, Miller DL, Balter S, et al; Joint Inter-Society Task Force on Occupational Hazards in the Interventional Laboratory. Occupational health hazards in the interventional laboratory: time for a safer environment. J Vasc Interv Radiol 2009;20(2):147-152

23 Nelson EM, Monazzam SM, Kim KD, Seibert JA, Klineberg EO. Intraoperative fluoroscopy, portable X-ray, and $\mathrm{CT}$ : patient and operating room personnel radiation exposure in spinal surgery. Spine J 2014;14(12):2985-2991

24 Christodoulou EG, Goodsitt MM, Larson SC, Darner KL, Satti J, Chan HP. Evaluation of the transmitted exposure through lead equivalent aprons used in a radiology department, including the contribution from backscatter. Med Phys 2003;30(6):1033-1038

25 Luchs JS, Rosioreanu A, Gregorius D, Venkataramanan N, Koehler V, Ortiz AO. Radiation safety during spine interventions. J Vasc Interv Radiol 2005;16(1):107-111

26 Pitteloud N, Gamulin A, Barea C, Damet J, Racloz G, Sans-Merce M. Radiation exposure using the 0 -arm ${ }^{\circledR}$ surgical imaging system. Eur Spine J 2017;26(3):651-657

27 Scarone P, Vincenzo G, Distefano D, et al. Use of the Airo mobile intraoperative CT system versus the 0 -arm for transpedicular screw fixation in the thoracic and lumbar spine: a retrospective cohort study of 263 patients. J Neurosurg Spine 2018;29(4):397-406

28 Ulmer S, Schulz E, Moeller B, et al. Radiation dose of the lens in trans-sphenoidal pituitary surgery: pros and cons of a conventional setup using fluoroscopic guidance and CT-based neuronavigation. Am J Neuroradiol 2007;28(8):1559-1564

29 Yu E, Khan SN. Does less invasive spine surgery result in increased radiation exposure? A systematic review. Clin Orthop Relat Res 2014;472(6):1738-1748

30 Narain AS, Hijji FY, Yom KH, Kudaravalli KT, Haws BE, Singh K. Radiation exposure and reduction in the operating room: perspectives and future directions in spine surgery. World J Orthop 2017;8(7):524-530

31 Rumboldt Z, Huda W, All JW. Review of portable CT with assessment of a dedicated head CT scanner. AJNR Am J Neuroradiol 2009;30(9):1630-1636

32 Detorie N, Mahesh M, Schueler BA. Reducing occupational exposure from fluoroscopy. J Am Coll Radiol 2007;4(5):335-337

33 Thomton FJ, Paulson EK, Yoshizumi TT, Frush DP, Nelson RC. Single versus multi-detector row CT: comparison of radiation doses and dose profiles. Acad Radiol 2003;10(4):379-385

34 Pennington Z, Cottrill E, Westbroek EM, et al. Evaluation of surgeon and patient radiation exposure by imaging technology in patients undergoing thoracolumbar fusion: systematic review of the literature. Spine J 2019;19(8):1397-1411

35 Hayashi N, Sakai T, Kitagawa M, et al. Radiation exposure to interventional radiologists during manual-injection digital subtraction angiography. Cardiovasc Intervent Radiol 1998;21(3):240-243

36 Okamoto K, Ito J, Sakai K, Yoshimura S. The principle of digital subtraction angiography and radiological protection. Interv Neuroradiol 2000;6(Suppl 1) :25-31

37 Telischak NA, Heit JJ, Campos LW, Choudhri OA, Do HM, Qian X. Fluoroscopic C-arm and CT-guided selective radiofrequency ablation for trigeminal and glossopharyngeal facial pain syndromes. Pain Med 2018;19(1):130-141

38 Braun E, Sack AM, Sayed D, et al. Reducing radiation exposure in lumbar transforaminal epidural steroid injections with pulsed fluoroscopy: a randomized, double-blind, controlled clinical trial. Pain Physician 2018;21(1):53-60

39 Fan Chiang CY, Tsai TT, Chen LH, et al. Computed tomography-based navigation-assisted pedicle screw insertion for thoracic and lumbar spine fractures. Chang Gung Med J 2012;35(4):332-338

40 Xie Z, Liao X, Kang Y, Zhang J, Jia L. Radiation exposure to staff in intensive care unit with portable CT scanner. BioMed Res Int 2016;2016:5656480

41 McTyre E, Helis CA, Farris M, et al. Emerging indications for fractionated gamma knife radiosurgery. Neurosurgery 2017;80(2):210-216

42 Koga T, Shin M, Saito N. Role ofknife radiosurgery in neurosurgery: past and future perspectives. Neurol Med Chir (Tokyo) 2010;50(9):737-748

43 Miller DC, Patel J, Smith CC; Spine Intervention Society's Patient Safety Committee. Fact finders for patient safety: radiation safety for interventional spine procedures. Pain Med 2018;19(3):629-630

44 Dromi S, Wood BJ, Oberoi J, Neeman Z. Heavy metal pad shielding during fluoroscopic interventions. J Vasc Interv Radiol 2006;17(7):1201-1206

45 Delichas M, Psarrakos K, Molyvda-Athanassopoulou E, et al. Radiation exposure to cardiologists performing interventional cardiology procedures. Eur J Radiol 2003;48(3):268-273

46 Marichal DA, Anwar T, Kirsch D, et al. Comparison of a suspended radiation protection system versus standard lead apron for radiation exposure of a simulated interventionalist. J Vasc Interv Radiol 2011;22(4):437-442

47 Schueler BA, Vrieze TJ, Bjarnason H, Stanson AW. An investigation of operator exposure in interventional radiology. Radiographics 2006;26(5):1533-1541

48 Haussen DC, Van Der Bom IM, Nogueira RG. A prospective case control comparison of the ZeroGravity system versus a standard lead apron as radiation protection strategy in neuroendovascular procedures. J Neurointerv Surg 2016;8(10):1052-1055

49 Lichliter A, Weir V, Heithaus RE, et al. Clinical evaluation of protective garments with respect to garment characteristics and manufacturer label information. J Vasc Interv Radiol 2017;28(1):148-155

50 Pasciak AS, Jones AK. Time to take the gloves off: the use of radiation reduction gloves can greatly increase patient dose. J Appl Clin Med Phys 2014;15(6):5002

51 Karadag B, Ikitimur B, Durmaz E, et al. Effectiveness of a lead cap in radiation protection of the head in the cardiac catheterisation laboratory. EuroIntervention 2013;9(6):754-756

52 International Electrotechnical Commission Report 60601. Medical electrical equipment 2000; Part 2-43: particular requirements for the safety of $\mathrm{x}$-ray equipment for interventional procedures. International Electrotechnical Commission, Geneva, Switzerland

53 Multimedia and audio-visual radiation protection training in interventional radiology (MARTIR), radiation protection 119. European Commission; 2002. Available at: http://ec.europa. eu/energy/wcm/nuclear/cd_rom_martir_project.zip

54 IAEA. Diagnostic and interventional radiology. Available at: http://rpop.iaea.org/RPOP/RPoP/Content/ AdditionalResources/Training/1_TrainingMaterial/Radiology. $\mathrm{htm}$. A training documentation regarding radiation protection from the IAEA. Accessed March 1, 2020 